\title{
КОГНИТИВНЫЕ НАРУШЕНИЯ У БОЛЬНЫХ С МЕРЦАТЕЛЬНОЙ АРИТМИЕЙ
}

\author{
${ }^{1}$ Хайриева М.Ф., ${ }^{2}$ Гафуров Б.Г.* \\ ${ }^{\prime}$ Бухарский Медииинский Институт, Бухара, Узбекистан; \\ ${ }^{2}$ Ташкентский Институт Усовершенствования Врачей, кафедра неврологии, Ташкент, Узбекистан
}

В работе с помощью набора нейропсихологических тестов, направленных на оценку когнитивных функций (тесты MMSE, FAB, рисования циферблата часов, запоминания 10 слов) обследовано 84 пациента ишемической болезнью сердца (ИБС), в том числе 20 без мерцательной аритмии (МА) и 64 с МА. Последние разделены на подгруппы с постоянной (22 пациента) и приступообразной (42 пациента) формами МА. Результаты показали, что у больных ИБС с МА развиваются более выраженные когнитивные нарушения (КН), по сравнению с ИБС без нарушения ритма. При этом, пароксизмальный вариант МА ассоциирует с более выраженными КН, чем перманентный. Авторы заключают, что КН при ИБС с МА требуют большого внимания, как в отношении диагностики, так и лечения.

Ключевые слова: когнитивные нарушения, мерцательная аритмия, перманентная и персистирующая формы мерцательной аритмии.

Введение. Мерцательная аритмия является самой распространенной формой нарушения сердечного ритма и одной из наиболее частых причин тяжелых церебральных осложнений, таких как тромбоэмболический инсульт, транзиторные ишемические атаки и хроническая ишемия мозга $[1,2,7,10,13,14]$. Основной причиной этих осложнений является нарушение сердечного выброса, его значительные перепады и, как следствие, гипоперфузия не только в мозге, но и в других жизненно важных органах, в том числе и в самом сердце. Это запускает целую цепную реакцию патологических изменений во всём организме, включающую значительные метаболические, нейроэндокринные и другие сдвиги. Всё это не может не отражаться на когнитивных функциях пациента.

Следует отметить, что в вопросах патогенеза и клиники когнитивных нарушений при патологии сердца ещё много неясного. Описано множество вероятных причин развития когнитивных нарушений при сердечно-сосудистых заболеваниях $[5,10,11]$. Среди них выделяют разобщение связей лобных долей с другими отделами головного мозга в результате диффузных изменений белого вещества, возникших на фоне снижения перфузии вещества головного мозга. Кроме того, хорошо известно, что патология лобных отделов коры приводит к нарушению исполнительного контроля и развитию «регуляторных» когнитивных нарушений $[2,3,5,8]$. Также в ряде работ показано, что выраженность нарушений исполнительных функций и снижение скорости психо- моторных процессов коррелирует с выраженностью микроструктурных изменений в задних отделах головного мозга $[5,12]$. Данным фактом также объясняется ухудшение показателей нейропсихологических тестов зрительного восприятия информации, поскольку известно о локализации коркового представительства зрительного анализатора в затылочных долях головного мозга. Кроме того, гипоксия мозговой ткани на фоне снижения сердечного выброса является фактором, ускоряющим нейродегенеративные изменения, причем, особенно чувствительны к гипоксии нейроны гиппокампа [4].

Однако все эти данные касаются в основном постоянной формы мерцательной аритмии (ПМА). При персистирующей форме мерцательно аримии (ПсМА) возникают те же патофизиологические условия и реализуются те же механизмы, что и при постоянно существующей МА. Формирование тромбов в полостях сердца при МА связано больше с персистирующей формой и наличием всех трех компонентов триады Вирхова: стаза крови, активации каскада коагуляции и дисфункции эндотелия $[2,5,6,9,10$, 12]. Повышенный риск тромбообразования у 38-80\% больных сохраняется в течение нескольких недель после успешной кардиоверсии [13]. При ПсМА помимо кардиоцеребральной эмболии в повреждение мозговой ткани вносят вклад гемодинамические нарушения, которые нарушают физиологическую реактивность сосудов, в первую очередь микроциркуляторного русла [2, $5-7,13]$. При этом снижение артериального дав-

*e-mail: cool.bahtiyar@yandex.com 
ления в результате уменьшения сердечного выброса при ПсМА приводит к возникновению гипоперфузии в зонах терминального кровообращения - глубинных отделах белого вещества головного мозга и базальных ганглиях. Работ по изучению когнитивных нарушений при ПсМА в литературе недостаточно.

Цель исследования. Изучить значение мерцательной аритмии и её разных клинических вариантов как фактора риска наличия когнитивных расстройств (КР) у больных с ишемической болезнью сердца (ИБС).

Материалы и методы исследования. Критериями включения в исследование были наличие у пациентов документированной МА и кардиоваскулярного заболевания (ИБС и/или артериальная гипертензия). Контрольную группу составили пациенты без нарушения сердечного ритма на ЭКГ, страдающие теми же сердечнососудистыми заболеваниями. Основную группу мы разделили на две подгруппы пациентов - с ПсМА и с постоянной (перманентной) мерцательной аритмией (ПМА). В группу с ПсМА вошли больные, у которых МА была купирована в течение 2 суток нахождения больных в стационаре фармакологической, либо электрической кардиоверсией. В группу с ПМА входили пациенты с МА длительностью более года, восстановление синусового ритма у которых было нестойким (неудачным), либо не проводилось вовсе.

Группу больных с ПМА составили 22 пациента, средний возраст которых также был 57,3 $\pm 1,6$ лет. Группу больных с ПсМА составили 42 пациента, их средний возраст - 59,5 2 лет. Контрольную группу (КГ) составили 20 пациентов без явных нарушений ритма, страдающих кардиоваскулярной патологией в возрасте от 49 до 65 лет. Признаки умеренной сердечной недостаточности I-II функционального класса выявлены у 55 больных, III - у 29. При сравнении по этому показателю основные группы пациентов и группа сравнения были сопоставимы.

Методы исследования включали клиническое неврологическое обследование и нейропсихологическое тестирование. Для оценки общей тяжести когнитивных нарушений использовались суммарные показатели основных скрининговых нейропсихологических тестов: краткой шкалы оценки психического статуса (англ. Mini Mental State Examination - MMSE), батареи тестов для оценки лобной дисфункции - (англ. Frontal Assessment Battery - FAB). Для оценки пространственных функций использовался тест рисования циферблата часов по заданию (ТРЧ). Проводился также тест на запоминание 10 слов. Статистическая обработка проводилась параметрическими и непараметрическими методами [4].

Результаты. Как видно из таблицы ниже, у пациентов всех трёх групп $(n=84)$ по данным нейропсихологического тестирования выявлено снижение балльных показателей когнитивных функций относительно стандартной нормы. При этом в группах больных с МА они были существенно хуже, по сравнению с КГ. Из таблицы видно, что когнитивные нарушения по тесту FAB достоверно превалируют по сравнению с КГ при обеих группах больных с МА, а по тестам MMSE и ТРЧ они достоверно хуже, по сравнению с КГ, в группе с ПсМА. Средние показатели по тесту MMSE в группах больных не имели достоверных различий между собой, однако по тестам FAB и ТРЧ между группами с ПМА и ПсМА выявлены достоверно более худшие показатели в группе с ПсМА.

Внутри обследованных трёх групп больных имел место разброс балльных показателей по шкале MMSE, хотя по средним показателям эти различия нивелировались. Поэтому мы решили всех обследованных больных, включая КГ, разделить по показателям шкалы MMSE на три группы с лёгкими когнитивными нарушениями (ЛКН, ниже 27 баллов), умеренными (УКН, ниже 25 баллов) и выраженными, ниже 23 баллов). ЛКН выявлены у 26 пациентов (30,9\%), УКР соответственно у 37 (44,0\%) и ВКР у 21 (25,1\%) (таб.).

Из таблицы видно, что в обеих группах больных с МА нарушения когнитивных функций по тесту FАВ и ТРЧ достоверно более выражены, по сравнению с КГ независимо от степени выраженности когнитивного дефекта по тесту MMSE. На этом фоне отмечается, что по мере нарастания общей выраженности когнитивных нарушений различия между группами с ПМА и ПсМА становятся выраженными и статистически значимыми. Это видно из сопоставления показателей тестов FАВ и ТРЧ внутри групп с 
Показатели когнитивных функций у больных ИБС в зависимости от наличия и отсутствия мерцательной аритмии

\begin{tabular}{|c|c|c|c|c|c|}
\hline Тесты & Группы & $\begin{array}{c}\text { Средние показатели } \\
\text { в баллах }\end{array}$ & ЛКР & УКР & BKP \\
\hline MMSE & $\begin{array}{l}\text { КГ } \\
\text { ПМА } \\
\text { ПсMА }\end{array}$ & $\begin{array}{l}25,9 \pm 1,29 \\
25,6 \pm 1,36 \\
25,2 \pm 1,20^{*}\end{array}$ & $26(30,9 \%)$ & $37(44,0 \%)$ & $21(25,1 \%)$ \\
\hline FAB & $\begin{array}{l}\text { КГ } \\
\text { ПМА } \\
\text { ПсМА }\end{array}$ & $\begin{array}{l}26,0 \pm 1,23 \\
25,5 \pm 1,13^{* \wedge} \\
25,0 \pm 1,30^{* \wedge}\end{array}$ & $\begin{array}{l}28,3 \pm 1,2 \\
27,5 \pm 1,1^{*} \\
27,2 \pm 1,4^{*}\end{array}$ & $\begin{array}{l}25,9 \pm 1,1 \\
25,6 \pm 1,3^{* \wedge} \\
25,1 \pm 1,2^{* \wedge}\end{array}$ & $\begin{array}{l}23,8 \pm 1,4 \\
23,4 \pm 1,1^{* \wedge} \\
22,6 \pm 1,3^{* \wedge}\end{array}$ \\
\hline ТРЧ & $\begin{array}{l}\text { КГ } \\
\text { ПМА } \\
\text { ПсMА }\end{array}$ & $\begin{array}{l}7,8 \pm 1,43 \\
7,7 \pm 1,27^{\wedge} \\
7,3 \pm 0,82^{* \wedge}\end{array}$ & $\begin{array}{l}9,1 \pm 0,4 \\
9,0 \pm 0,8^{*} \\
8,9 \pm 0,6^{*}\end{array}$ & $\begin{array}{l}7,8 \pm 2,6 \\
7,6 \pm 1,6^{* \wedge} \\
6,9 \pm 1,2^{* \wedge}\end{array}$ & $\begin{array}{l}6,4 \pm 1,3 \\
6,1 \pm 1,4^{* \wedge} \\
6,0 \pm 0,6^{* \wedge}\end{array}$ \\
\hline
\end{tabular}

Примечание: * - достоверность различий с контрольной группой; ^ - достоверность различий между основными группами больных $(\mathrm{p} \leq 0,05-0,01)$

\section{УКР и ВКР.}

Нарушения памяти отмечались у всех пациентов с УКР и ЛКР, но у пациентов с ВКР они были достоверно $(\mathrm{p}<0,05)$ более выражены. В нашем исследовании у пациентов с УКР определялось 2 основных варианта синдрома когнитивных расстройств - дисмнестический вариант и нейродинамически-дизрегуляторный варианты когнитивных расстройств (КР). Основой для выделения у пациентов одного из вариантов синдрома КР послужили результаты теста на запоминание и воспроизведение 10 слов. Нарушения памяти у пациентов с КР дизрегуляторного варианта не устранялись организацией процесса запоминания и воспроизведения, а также введением семантических подсказок, что свидетельствовало о нарушениях памяти, обусловленных первичной дисфункцией гиппокампа $[5,7]$.

Заключение. Согласно полученным нами

\section{ЛИТЕРАТУРА - REFERENCES - ӘDӘВIYYYAT}

1. Алехин А.Н., Трифонова Е.А., Лебедев Д.С. Психологические проблемы в аритмологии (на модели фибрилляции предсердий) // Вестник аритмологии. 2011. №63. С. 45-54. 2. Ваниева О.С., Сидоренко Б.А. Современные стратегии лечения и выявление предикторов рецидива мерцательной аритмии. Трудный пациент. 2012; 10 (4): 17-23.

3. Гимоян Л.Г., Силванян Г.Г. Нарушение когнитивных функций: актуальность проблемы, факторы риска, возможности профилактики и лечения. Архив внутренней медицины. 2013; 2: 35-40.

4. Гублер, Е.В. Применение непараметрических критериев статистики в медико-биологических исследованиях / Л.: Медицина, 1973. - 144 с.

5. Дамулин И.В. Когнитивные расстройства при церебро- данным, наличие МА у больных ИБС существенно ослабляет когнитивные функции, включая память, внимание, пространственную ориентацию и локомоторные функции. Эти нарушения преобладают у пациентов с ПсМА по сравнению с группой с ПМА. Вероятно, периодически возникающие «атаки» МА оказывают большее негативное воздействие на состояние мозга и систему ауторегуляции мозгового кровообращения, чем постоянная форма аритмии. Последняя, вероятно, в какой-то степени мобилизует компенсаторные механизмы.

Результаты исследования показывают, что когнитивные нарушения могут быть достоверными показателями вовлечения в патологический процесс при ИБС с МА такого важного «органа-мишени», как головной мозг и требуют к себе большого внимания как в плане диагностики, так и лечения.

васкулярной патологи // Журнал неврологии и психиатрии. 2009. №1. С. 75-80.

6. Диагностика и лечение фибрилляции предсердий. Рекомендации ВНОК и ВНОА, 2011. [Электронный ресурс].

7. Ковалева О.Н., Демиденко А.В. Диагностическое значение определения комплекса интима-медиа для оценки особенностей ремоделирования и атеросклеротического поражения сосудов. 2009 [Электронный ресурс]. http://biosite.ru/articles/10/69.

8. Левин О.С. Когнитивные нарушения в практике терапевта: заболевания сердечно-сосудистой системы // Consilium Medicum. 2009. № 11 (2). С. 55-61.

9. Лурия А.Р. Высшие корковые функции человека. Изд.2. 
М.: Изд-во Московского Университета, 1969. 431 с.

10. Фонякин А.В., Машин В.В., Гераскина Л.А. и соавт. Кардиогенная энцефалопатия. Факторы риска и подходы к терапии // Consilium medicum. 2009. №9. С. 37-41.

11. Ball J., Carrington M.J., McMurray J.J. et al. Atrial fibrillation: profile and burden of an evolving epidemic in the $21 \mathrm{st}$ century. Int. J. Cardiol. 2013; 167 (5): 1807-24.

12. Chugh S.S., Havmoeller R., Narayanan K. et al.
Worldwide epidemiology of atrial fibrillation: a Global Burden of Disease 2010 Study. Circulation. 2014; 129 (8): 837-47.

13. Schnabel R.B., Rienstra M., Sullivan L.M. et al. Risk assessment for incident heart failure in individuals with atrial fibrillation. Eur. J. Heart Fail. 2013; 15 (8): 843-9.

14. Menke J., Lüthje L., Kastrup A. et al. Thromboembolism in atrial fibrillation. Am. J. Cardiol. 2010; 105 (4): 502-10.

\title{
XÜLASə
}

\section{SəYİRICI ARITMIYALI XəSTəLӘRDə KOQNITIV POZULMALAR}

\author{
${ }^{1}$ Xayriyeva M.F., ${ }^{2}$ Qafurov B.Q. \\ 'Buxara Tibb İnstitutu, Buxara, Özbəkistan; \\ ${ }^{2}$ Daşkəand Həkimlari Təkmillaşdirma İnstitutu, nevrologiya kafedrası, Daşkənd, Özbəkistan
}

Təqdim edilmiş məqalədə koqnitiv funksiyaların qiymətləndirilməsi üçün nəzərdə tutulmuş neyropsixoloji testlərin köməyi ilə (MMSE, FAB testləri, saat siferblatının çəkilməsi testi, 10 söz yadda saxlama testi) ürəyin işemik xəstəliyi (ÜIX) olan 84 pasiyent müayinə edilmişdir, bunlardan 20 pasiyent səyirici aritmiyası (SA) olmayan, 64 nəfər səyirici aritmiyalı. Sonuncular daimi (22 pasiyent) və keçici (42 pasiyent) SA olan yarımqruplara bölünmüşdür. Nəticələr göstərdi ki, ÜIX və SA olan xəstələrdə digər qrupla müqayisədə daha qabarıq koqnitiv pozulmalar (KP) inkişaf edir. Bununla yanaşı, SA-nın paroksizmal variantı permanent variantla müqayisədə daha qabarıq KP ilə assosiasiya olunur. Müəlliflərin fikrincə ÜİX və SA birlikdə olan xəstələrdə KP diaqnostika və müalicə baxımından daha böyük diqqət tələb edir.

Açar sözlər: koqnitiv pozulmalar, səyirici aritmiya, permanent və persistəedici səyirici aritmiya.

\section{SUMMARY}

\section{COGNITIVE IMPAIRMENT IN PATIENTS WITH ATRIAL FIBRILLATION}

\author{
${ }^{1}$ Hairieva M.F., ${ }^{2}$ Gafurov B.G. \\ ${ }^{\prime}$ Bukhara medical Institute, Bukhara, Uzbekistan; \\ ${ }^{2}$ Tashkent Advanced Training Institute for doctors, department of neurology, Tashkent, Uzbekistan
}

84 patients with coronary heart disease (CHD), including 20 patients without atrial fibrillation (AF) and 64 patients with AF, were examined using a set of neuropsychological tests aimed at assessing cognitive functions (MMSE, FAB, clock face drawing, memorization of 10 words). The latter were divided into subgroups with permanent (22 patients) and paroxysmal (42 patients) forms of AF. The results showed that patients with CHD and AF develop more pronounced cognitive impairment (CI), compared to CHD without rhythm disturbance. In this case, the paroxysmal variant of $\mathrm{AF}$ is associated with more pronounced CI than the permanent one. The authors conclude that CI in CHD with AF requires great attention both in terms of diagnosis and treatment.

Keywords: cognitive impairment, atrial fibrillation, permanent and persistent forms of atrial fibrillation. 